Revista STUDIUM N. ${ }^{\circ} 2-3,2001$ (pp. 147-150)

\title{
EL DESEO DERROTARÁ LAS NUEVAS ESCLAVITUDES
}

Dr. Giorgio Vittadini

(Catedrático de Estadística de la Universidad de Milán)

Estamos en los inicios de la revolución de la Neñ / Net Economy, en los primeros pasos en Italia, y ya se perfilan dos posiciones contrapuestas y casi correspondientes. Existe aquella pasiva de aceptación actítica, del nuevo mundo de la red que ve un futuro definido por escenarios encantadores, aunque los nuevos medios tecnológicos no lograran resolver ellos mismos el problema humano, Existe otra posición, de una profunda inquietud, que se realiza confusamente con las cadenciosas manifestaciones del llamado pueblo de Seattle, en rabioso contraste contra la globalización. Cada una de estas dos posiciones tiene sus propios intérpretes, más o menos conocidos.

Algunos años atrás, el cosmólogo americano Frank J. Tippler veía en la computadora el instrumento que podía acercarlo a Dios. Se preguntaba Tippler: “¿Es posible, con la computadora, crear un proyecto de universo o de cosmos? Si esto fuera posible, ¿no ha sido la tarea del Creador? De la fantasmagórica neognóstica de Tipper, en el acrisolarse en una idolatría fuera de lugar, se puede descender hasta la pasividad inconsciente de los nueyos oyentes de los noticieros nocturnos del Nasdaq, donde la trama compleja de relaciones humanas de la vieja y de la nueva economía se resuelven en un frío cociente algebraico que provoca felicidad o desaliento.

Al otro lado de la barricada están las elaboraciones de los nuevos intérpretes de una izquierda antigua que, de frente a los nuevos medios, reelaboran la teoria del contraste de clases y de poder, entre los iniciados en la red informática y los nuevos intocables, los parias que estarán al margen de la humanidad, guiada por una nueva casta sacerdotal, el nuevo poder fuerte que sabe interpretar los signos de la nueva tecnología. De las páginas de un analista de la sociedad como Jeremy Rifkin, también emerge un escenario angustiante.

En ambas posiciones, a lo mejor, hay una exaltación, divina a demoníaca, del instrumento, del medio, de la tecnología electrónica, que estaría en la facuitad de 


\section{Dr. Giorgio Vittadini}

comprimir, de anular la originalidad, la creatividad de la persona humana, su complejidad, su unicidad.

Tratemos entonces de ubicarnos en el horizonte de este mundo nuevo, en esta aldea global donde se desplazan gran cantidad de dinero y de mercancía en tiempo real, donde la dimensión del espacio parece desvanecerse frente a la velocidad de la luz y a la llamada interactividad producida por los new media electrónicos.

No cabe ninguna duda que los nuevos instrumentos, el nuevo medio y la red, como toda la historia de la tecnología demuestra, cambian las relaciones sociales y condicionan la vida de un modo distinto, hasta rediseñarse los mismos comportamientos humanos. Pero muy a menudo se ha confundido la fuerza de la tecnología con el uso violento de la tecnología.

Escritores como George Orwell en 1984 y Ray Bradbury en Fabrenheit 451, un artista como Orson Wells en Cuarto poder han intuido y descrito el mundo de la deshumanización mediática. Pero del mismo drama de la toma de conciencia, del grito de protesta de una búsqueda de humanidad, puede nacer la esperanza, fundada sobre la originalidad y la unicidad del hombre.

Además, de la lectura atenta de la obra de estos escritores y de estos artistas se puede ver que el impacto entre instrumento y hombre es sólo un aspecto del drama. El impacto más fragoroso está entre el hombre, en su deseo de creatividad y de libertad, y quien tiene la posesión, el poder del instrumento, y lo usa de modo deshumanizado, en contra del hombre, a favor de un esquema ideológico propio. El antidoto al condicionamiento del instrumento $\mathrm{y}$, todavía de más, la voluntad de contrastar el designio ideológico de quien posee la tecnología, está precisamente en el hombre mismo, en su naturaleza, en su pasión, en su deseo.

Escribió Juan Pablo I en su primera encíclica Redemptor Hominis del 4 de marzo de 1979: "El hombre, en la plena verdad de su existencia, de su ser personal y a la vez de su ser comunitario y social en el ámbito de la familia, en el ámbito de la sociedad y de contextos tan diversos, en el ámbito de la propia naciónn, o pueblo (y posiblemente, sólo aún del clan, o tribu) en el ámbito de toda la humanidad-erte bombre es el primet camino que la Iglesia debe recorrer en el cumplimiento de su misión, él es camino primeto y fundamental de la Iglesia, camino trazado por Cristo mismo, via que inmutablemente conduce a través del misterio de la Encarnación y de la Redención". 


\section{EL DESEO DERROTARÁ LAS NUEVAS ESCLAVITUDES}

Dice don Luigi Giussani que el hombre es movido por un deseo. El deseo es como la chispa que enciende el motor. Todos los movimientos humanos nacen de este fenómeno, de este dinamismo constructivo del hombre. El deseo enciende el motor del hombre. Y es precisamente del deseo del que depende la creatividad del hombre. Añade Don Giussani que el hombre es más complejo que el elenco analítico de necesidades fijadas por los sociólogos y psicólogos de turno. El hombre no es reconducible a ningún esquema analítico. El hombre tiene una necesidad absoluta de crear, en cualquier modo, la realidad.

\section{El significado de "Total Quality"}

Basta observar con racionalidad, sí precisamente con racionalidad, la pasión que anima al hombre por todos aquellos que tiene alrededor. La pasión y el deseo con los que un hombre quiere que los otros estén mejor y sean sus amigos. La pasión con la que se pone a la obra para construir una empresa. Los estudiosos de los mecanismos económicos de la empresa moderna han debido coincidir en que una empresa no es sólo productividad, capacidad, tecnología, medios. El nuevo concepto de total quality se puede traducir correctamente sólo agregando el aspecto humano, es decir, que, quien actúe en la empresa deba creer también en ella, con pasión. En realidad, es necesario convenir en que al hombre no se le puede encasillar, que su creatividad es tan impetuosa que sólo un poder, violento o sutilmente cínico, puede comprimirla con un instrumento, un medio tecnológico, pero no puede extirparla de ninguna manera.

Aquel poder que debería poner en acto esta operación (como ya ha sucedido en el pasado), puede solamente retardar el camino de la humanidad hacia su deseo último, puede crear un lager de violencia o de promesas, puede detener por un cierto periodo la historia del hombre, incluso puede elaborar nuevas formas económicas basadas en la esclavitud, pero no podrá nunca apagar el deseo que está en el corazón del hombre. Entonces, el verdadero problema no es el instrumento tecnológico, sino quien posee el poder de los instrumentos.

Retornemos entonces al condicionamiento instrumental que la new economy o la red pueden utilizar. Quizás estamos frente a una revolución mayor que aquella que ocurrió cuando hubo el cambio de la linotipia a la fotocomposición. La masa de señales y de datos que pueden ser intercambiadas a puesta a disposición es impensable. Ya se empiezan a acunar neologismos como teleputer o compupisión, para definir el televisor que se vuelve computadora o la computadora que se vuelve televisor. Y, afirman los 


\section{Dr, Giorgio Vittadiní}

expertos, cuando se superen los limites actuales entre televisión y computadora nos enfrentaremos a una nueva fase de revolución mediática.

Solamente esto nos puede ofrecer una idea de cómo cambiarả el modo de trabajar de cada hombre y por ende, de su condición de vida. Se podrian hacer centenares de ejemplos. La aldea electrônica, la globalización, ciertamente tendrán al principio un lenguaje para los iniciados. ¿Cómo se podrá prescindir de los conocimientos del inglés y de la informática para una alfabetización que consienta el uso de la red? Todo esto, posiblemente, creará un nuevo modo de lenguaje humano, probablemente también un proceso lógico diferente de la lógica que ha sido enseñada en los bancos universitarios hasta algunos años atrás. ¿Todo esto debe asustarnos? ¿'Todo esto debe comprometer la creatividad, el deseo del hombre? ¿Cómo puede un cristiano. asustarse frente al nuevo mundo de la comunicación, si Dios mismo ha entrado en comunicación con el hombre a través del mundo y un libro, la Biblia?

En realidad, nosotros tenemos el temor natural que se experimenta frente a lo. nuevo y lo desconocido. Pero, al mismo tiempo, también tenemos la conciencia de entender pronto que poseer mayor conocimiento, tener, por ejemplo, mayores datos a disposición sobre una epidemia, nos puede permitir intervenir de un modo como nunca se hizo en el pasado. Poder disfrutar de informaciones inmediatas sobre los mercados nos permite facilitar la venta de productos de pequeñas y medianas empresas que no han tenido en el pasado oportunidades de un marketing adecuado. Quizás uno de los pocos spots televisivos acertados es aquel de una señora anciana de un pueblito italiano que dice a los turistas americanos que están de paso: "yo vendo mis quesos en los Estados Unidos".

En realidad, la red informática no debe ser ni adorada ni condenada. La red es un instrumento construido por la creatividad humana y como tal debe ser utilizada por los hombres. Paradójicamente, la red nos impone, en su casi ilimitada capacidad de comunicación, una mayor reflexión sobre nuestra identidad humana, sobre nuestra naturaleza de hombres. $Y$ aquí retornamos a aquel misterioso vínculo de pertenencia que liga a los hombres entre ellos y que les hace disparar, cuando toman conciencia, el deseo. Como frente a cada época tecnológica, el deseo empujará al hombre a buscar el pan y el agua, a interesarse por sus problemas y los problemas de los otros, a mejorar sus condiciones y la de sus hermanos hombres. No planteando futuros ideológicos, no hincándose o retrayéndose atemorizado, el hombre con su deseo también derrotará los condicionamientos de la red informática. 